\title{
CARBONO, NITROGÊNIO E FÓSFORO MICROBIANO DO SOLO SOB DIFERENTES COBERTURAS EM POMAR DE PRODUÇÃO ORGÂNICA DE MAÇÃ NO SUL DO BRASIL $\left({ }^{1}\right)$
}

\author{
DENICE ALMEIDA $\left(2^{*}\right)$; OSMAR KLAUBERG FILHO $\left({ }^{3}\right)$; ALINE FRANCIANE FELIPE $\left({ }^{3}\right)$; \\ HENRIQUE CESAR ALMEIDA $\left({ }^{2}\right)$
}

\begin{abstract}
RESUMO
O uso de coberturas sobre o solo constitui-se em alternativa na prevenção de plantas invasoras nos plantios orgânicos que excluem a utilização de herbicidas. Entretanto, existem poucos estudos no sul do Brasil sobre a implicação da cobertura do solo em sua qualidade microbiológica. Assim, o objetivo deste trabalho foi avaliar em duas épocas distintas o efeito de diferentes tipos de cobertura do solo nos atributos de carbono, nitrogênio e fósforo microbiano de um Latossolo com produção orgânica de maçã no sul do Brasil. O estudo foi realizado na Estação Experimental da Embrapa em Vacaria (RS) em delineamento experimental de blocos ao acaso. As coberturas estudadas foram: acícula, serragem e plástico preto comparadas ao solo descoberto e com plantas invasoras. As amostras de solo foram coletadas em fevereiro (verão) e agosto (inverno) de 2006, sendo determinados atributos microbianos e químicos relacionados ao carbono, nitrogênio e fósforo. As coberturas orgânicas (acícula e serragem) promoveram maior umidade e maiores teores de Cmic, Nmic, Corg, maior relação Cmic/Corg, Nmic/Ntotal e C/N microbiano. A cobertura com plástico preto e solo descoberto promoveu maior temperatura, nitrato, quociente metabólico e fósforo imobilizado na biomassa. Com base neste estudo e considerando a qualidade microbiana do solo as melhores coberturas foram as orgânicas.
\end{abstract}

Palavras-chave: Atributos microbianos, matéria orgânica, pomar orgânico.

\section{ABSTRACT \\ MICROBIAL CARBON, NITROGEN AND PHOSPHORUS ON SOIL UNDER DIFFERENT MULCHINGS IN ORGANIC APPLE ORCHARD IN SOUTHERN OF BRAZIL}

The use of soil mulching is an alternative in the prevention of weeds in organic orchard, which exclude the use of herbicides. However, there are few studies in southern Brazil on the impact of soil mulching in the soil microbiological quality. In this sense, the purpose of this study was to evaluate in two different seasons the effect of different types of soil mulching in the attributes of microbial carbon, nitrogen and phosphorus in a Typic Hapludox producing of organic apples in southern Brazil. The study was conducted at the Experimental Station of Embrapa in Vacaria, Rio Grande do Sul State, in a randomized block design. The mulchings were: pinus needle, wooden dust and black plastic compared to bare soil and weeds. Soil samples were collected in February (summer) and August (winter), 2006, with analysis microbial and chemical attributes related to carbon, nitrogen and phosphorus. Organic mulching (pinus needle and wooden dust) promoted higher soil moisture and higher levels of Cmic, Nmic, Corg, greater ratio Cmic/Corg, Nmic/Ntotal and microbial C/N. Black plastic mulching and bare soil promoted higher temperature, nitrate, immobilized phosphorus in biomass and metabolic quotient. Based on this study and considering soil microbial quality the best mulching were the organics.

Key words: Microbial attributes, organic matter, organic orchard.

( $\left.{ }^{1}\right)$ Parte da dissertação de mestrado em Ciência do Solo da primeira autora, apresentada à Universidade do Estado de Santa Catarina (UDESC). Recebido para publicação em 18 de março de 2008 e aceito em 8 de julho de 2009.

$\left(^{2}\right)$ Estudante de doutorado da Universidade Federal do Rio Grande do Sul (UFRGS). E-mail: almeidadeni@yahoo.com.br. ${ }^{*}$ ) Autora correspondente.

$\left.{ }^{3}\right)$ Departamento de Solos da UDESC, Av. Luiz de Camões, 2090, Bairro Conta Dinheiro, 88520-000, Lages (SC). 


\section{INTRODUÇÃO}

A cultura da maçã possui grande representatividade no cenário da fruticultura nacional, principalmente na região sul do Brasil. Nos Estados do Rio Grande do Sul e de Santa Catarina, há um clima favorável para o desenvolvimento da macieira, pois a árvore necessita de temperaturas baixas para acúmulo de horas de frio (MalucheBARETTA et al., 2007). Esta região é caracterizada como subtropical, onde os invernos são mais rigorosos e os verões mais amenos, diferentemente das demais regiões brasileiras, de característica tropical (NIMER, 1989). Resulta em uma área colhida estimada em 37.399 hectares e quantidade produzida de 1.091 .801 toneladas o que corresponde a mais de $90 \%$ da produção nacional (IBGE, 2007).

No princípio do cultivo comercial da maçã no sul do Brasil, produzia-se no sistema convencional. Entretanto, a recente preocupação com o uso sustentado do solo, ou seja, a utilização de práticas conservacionistas, que fornece produtos agrícolas com menor uso de agroquímicos, fez difundir nesta região o sistema orgânico de produção de maçãs (MALUCHEBARETTA et al., 2006).

No sistema orgânico, ressalta-se um manejo diferenciado àquele adotado tradicionalmente, substituindo as intensas aplicações de agrotóxicos por sistemas alternativos para controle de doenças, pragas e plantas espontâneas na cultura. Nesta última, como substituição ao uso de herbicidas, é utilizada roçada ou capina manual, mantendo-se o solo descoberto, ou ainda podem ser utilizados diversos tipos de materiais para sua cobertura, como cascas, palhas, restos culturais ou plástico polietileno. Esta técnica de cobertura do solo, ou mulching, como também é conhecida, já é utilizada em diversas partes do mundo e em várias culturas (HAN e WAN, 1995; Oliveira e Souza, 2003; Li et al., 2004). Porém, em alguns atributos do solo, podem ser detectadas alterações com a utilização dessas coberturas, como umidade e temperatura, por exemplo; estas alterações variam de acordo com o tipo de cobertura utilizada (LiU, 2000).

Pouco se conhece sobre os efeitos do uso de coberturas no que diz respeito à qualidade do solo, em especial no que se refere à compartimentalização de nutrientes na forma de biomassa microbiana nas condições de clima do sul do Brasil. Os sistemas orgânicos de produção dependem da atividade microbiana para mineralização e ciclagem dos nutrientes. Portanto, em solos ativos biologicamente, a microbiota constitui um reservatório considerável de nutrientes acessíveis, tornando-se muito importante para a qualidade do sistema solo-planta (Monokrousos et al., 2006), sobretudo no que tange aos elementos mais importantes para o desenvolvimento da cultura, como o nitrogênio e o fósforo.

O carbono orgânico e o quociente metabólico $\left(q \mathrm{CO}_{2}\right)$ também constituem bons indicadores de manejos culturais do solo, pois inferem sobre ao ganho de carbono e a eficiência de utilização e conservação do mesmo no solo (ANDERSON, 1982; PARKinson e Coleman, 1991; GamaRoDrigues, 2008). Este trabalho teve por objetivo avaliar o efeito de diferentes coberturas do solo nos compartimentos de carbono, nitrogênio e fósforo microbiano de um Latossolo Bruno com produção orgânica de maçã no sul do Brasil.

\section{MATERIAL E MÉTODOS}

O estudo foi realizado em um pomar desenvolvido no sistema orgânico de produção de maçã, na cidade de Vacaria (RS), localizada a $28^{\circ} 33^{\prime} 00^{\prime \prime}$ de latitude sul e $50^{\circ} 47^{\prime} 00^{\prime \prime}$ de longitude oeste. A altitude média é de $954 \mathrm{~m}$ acima do nível do mar e o clima da região, caracterizado como mesotérmico úmido, $\mathrm{Cfb}$ segundo a classificação de Köppen. O pomar da variedade Galaxy foi implantado em 2003, em Latossolo Bruno distrófico típico (EMBRAPA, 1999) de formação basáltica, anteriormente com vegetação de campo nativo. O local possui um relevo regional suave ondulado e ondulado com as seguintes características químicas e granulométricas do solo: $\mathrm{pH}-\mathrm{H}_{2} \mathrm{O}=4,5$; fósforo extraível (Mehlich 1) = $3,0 \mathrm{mg} \mathrm{kg}^{-1}$; carbono orgânico total $=24 \mathrm{~g} \mathrm{~kg}^{-1}$; nitrogênio total $=2,1 \mathrm{~g} \mathrm{~kg}^{-1}$; alumínio trocável $=2,0$ $\mathrm{cmol}_{\mathrm{c}} \mathrm{kg}^{-1}$; argila $=670 \mathrm{~g} \mathrm{~kg}^{-1}$; silte $=270 \mathrm{~g} \mathrm{~kg}^{-1}$ e areia $=60 \mathrm{~g} \mathrm{~kg}^{-1}$.

Em 2003, foi instalado no pomar um experimento para avaliar o efeito de diferentes tipos de cobertura do solo, sendo utilizados os seguintes tratamentos: cobertura do solo com camada de $10 \mathrm{~cm}$ de acícula de pínus, $10 \mathrm{~cm}$ de serragem nova (serragem de pínus de indústria madeireira); plástico polietileno preto; capina a cada 30 dias (solo descoberto) e tratamento sem controle do crescimento de plantas espontâneas invasoras. As unidades experimentais foram constituídas de parcelas de um metro de largura na linha de plantio por sete metros de comprimento. Foram utilizadas três repetições de campo para cada tratamento, dispostas em blocos ao acaso. 
A acícula e a serragem utilizadas como cobertura foram adicionadas em um volume de $0,7 \mathrm{~m}^{3}$ ao solo com a seguinte composição química: carbono orgânico total $=390 \mathrm{~g} \mathrm{~kg}^{-1}$ e $385 \mathrm{~g} \mathrm{~kg}^{-1}$; nitrogênio orgânico total $=1,44 \mathrm{~g} \mathrm{~kg}^{-1}$ e $0,63 \mathrm{~g} \mathrm{~kg}^{-1}$; e fósforo orgânico total $=2,9 \mathrm{~g} \mathrm{~kg}^{-1} \mathrm{e} 2,8 \mathrm{~g} \mathrm{~kg}^{-1}$, respectivamente. As concentrações foram determinadas segundo o método para análise de resíduos orgânicos descrito em TeDEsCo et al. (1995).

Realizaram-se duas coletas de solo, em fevereiro (verão) e agosto (inverno) de 2006. Foram retiradas amostras compostas de solo de 0 a $10 \mathrm{~cm}$ de profundidade para análises biológicas e químicas. As amostras de solo foram retiradas com trado holandês, transportadas em isopor térmico e mantidas em refrigeração constante a $4{ }^{\circ} \mathrm{C}$. A seguir, as amostras foram passadas em peneira com malha de 2,0 $\mathrm{mm}$ e para cada análise seguiram-se os métodos descritos na sequência.

Para as análises do carbono ( $\mathrm{Cmic})$, nitrogênio (Nmic) e fósforo da biomassa microbiana (Pmic) foi utilizada a metodologia descrita por VANCE et al. (1987), em que se usou fumigação seguida de extração com sulfato de potássio para Cmic e Nmic, e com bicarbonato de sódio para extração de Pmic. Para determinação das concentrações de Cmic seguiu-se método descrito por WALKLEY e BLACK (1934), com oxidação úmida das amostras na presença de dicromato de potássio. A quantidade de Nmic foi estimada através do método Kjeldahl (BROOKEs et al., 1985, adaptado por De-Polli e Guerra, 1999). O Cmic e o Nmic foram obtidos através da diferença entre as amostras fumigadas e não fumigadas. A concentração de fósforo microbiano foi determinada em espectrofotômetro UV-VIS em comprimento de onda de 882 nm (BRoOKes et al., 1982). Calculou-se o Pmic através da diferença entre as amostras fumigadas e não fumigadas.

Para a respiração basal microbiana utilizou-se o método descrito por JäGGI (1976). Nesta, amostras de solo foram incubadas em frasco hermeticamente fechado contendo hidróxido de sódio e mantido a $25 \pm 0,5{ }^{\circ} \mathrm{C}$ por 48 horas. Após o período de incubação, interrompeu-se o processo pela adição de cloreto de bário e a quantidade de $\mathrm{C}-\mathrm{CO}_{2}$ foi obtida através da titulação com ácido clorídrico. As concentrações do carbono orgânico total, nitrogênio total, amônio, nitrato e fósforo extraível foram obtidas segundo método descrito em TeDESCO et al. (1995). Foram determinadas ainda a umidade gravimétrica $(\mathrm{Ug})$ e a temperatura do solo (Ts). Com base nessas determinações foram calculadas as relações: $\mathrm{Cmic} / \mathrm{Corg}$, Nmic/Ntotal, $\mathrm{Cmic} /$ Pmic, $\mathrm{C} / \mathrm{Nmic}$ e $q \mathrm{CO}_{2}$.
Os dados foram submetidos à análise de variância pelos métodos geométricos lineares (procedimento GLM) considerando-se tratamento, época e interação entre tratamento e época.

A comparação de médias foi realizada pelo teste de Bonferroni a 5\% de significância. Utilizou-se também a análise de correlação de Pearson para verificar possíveis relações existentes entre os diferentes atributos avaliados.

\section{RESULTADOS E DISCUSSÃO}

\section{Atributos relacionados ao carbono}

As coberturas orgânicas (acícula e serragem) proporcionaram os maiores teores de carbono microbiano ( $\mathrm{Cmic}$ ), carbono orgânico (Corg) e relação Cmic/Corg no solo em ambas as épocas estudadas (Tabela 1). Em contrapartida, a utilização do plástico sobre o solo ocasionou uma redução de aproximadamente $50 \%$ nos teores de Cmic e 18\% nos de Corg em relação aos demais tratamentos.

Com relação à sazonalidade, observou-se aumento de Cmic no solo do verão para o inverno quando se utilizou coberturas orgânicas, sendo estes da ordem de $37 \%$ e $21 \%$ respectivamente (Tabela 1 ). Comparando-se as diferentes coberturas em relação ao solo descoberto, houve aumento médio de $40 \%$ no Cmic no inverno com a utilização de acícula, serragem e plantas invasoras.

A maior concentração de Cmic no solo proporcionado pela acícula e pela serragem foi devido à decomposição gradual deste material pelos microrganismos do solo. Esses por sua vez mineralizam e utilizam parte do carbono como fonte de energia e nutriente, transformando-o em tecido microbiano. Em estudo realizado com coberturas na cultura do tomate em solo arenoso nos Estados Unidos, Tu et al. (2006) também constataram aumentos no Cmic no solo sob coberturas orgânicas. Neste caso, tal efeito independeu da época estudada.

Os resultados de Cmic e o Corg foram influenciados pela temperatura e a umidade do solo sob as coberturas utilizadas, o que pode ser comprovado pela existência de uma correlação positiva do Cmic com a umidade e negativa entre $\mathrm{Cmic}$ e Corg com a temperatura do solo (Tabela 2). 
Tabela 1. Carbono da biomassa microbiana (Cmic), carbono orgânico (Corg - média das duas épocas) e relação Cmic/ Corg e no verão (fevereiro/2006) e no inverno (agosto/2006), em sistema orgânico de produção de maçã sob diferentes coberturas do solo em Vacaria (RS)

\begin{tabular}{|c|c|c|c|c|c|}
\hline \multirow{3}{*}{ Tratamentos } & \multicolumn{2}{|c|}{ Cmic } & Corg & \multicolumn{2}{|c|}{ Cmic/Corg } \\
\hline & \multicolumn{2}{|c|}{ Época } & \multirow{2}{*}{ Média } & \multicolumn{2}{|c|}{ Época } \\
\hline & Verão & Inverno & & Verão & Inverno \\
\hline & \multicolumn{2}{|c|}{$-\mu g g^{-1}$} & $\mathrm{~g} \mathrm{~kg}^{-1}$ & \multicolumn{2}{|c|}{$\%$} \\
\hline Acícula & $248,16 \mathrm{abB}$ & $392,42 \mathrm{aA}$ & $28,44 \mathrm{a}$ & $1,09 \mathrm{ab}$ & $1,17 \mathrm{a}$ \\
\hline Serragem & $325,86 \mathrm{aB}$ & $415,10 \mathrm{aA}$ & $28,52 \mathrm{a}$ & $1,33 \mathrm{a}$ & $1,29 \mathrm{a}$ \\
\hline Plástico & $119,92 \mathrm{cA}$ & $142,09 \mathrm{bA}$ & $24,89 \mathrm{~b}$ & $0,57 \mathrm{~b}$ & $0,50 \mathrm{~b}$ \\
\hline Solo descoberto & $274,06 \mathrm{abA}$ & $229,07 \mathrm{bA}$ & $25,22 \mathrm{ab}$ & $1,28 \mathrm{a}$ & $0,80 \mathrm{~b}$ \\
\hline Plantas invasoras & 237,74 bA & $342,41 \mathrm{aA}$ & $26,08 \mathrm{ab}$ & $1,05 \mathrm{ab}$ & $1,16 \mathrm{a}$ \\
\hline CV (\%) & \multicolumn{2}{|c|}{11,66} & 7,07 & \multicolumn{2}{|c|}{15,87} \\
\hline
\end{tabular}

Letras iguais maiúsculas na linha (época) e minúsculas na coluna (tratamento) não diferem entre si a 5\% de significância pelo teste de Bonferroni.

Tabela 2. Correlação de Pearson entre os atributos carbono da biomassa microbiana (Cmic), relação Cmic/Corg, carbono orgânico (Corg), quociente metabólico $\left(q \mathrm{CO}_{2}\right)$, nitrogênio microbiano (Nmic), umidade gravimétrica (Ug), temperatura do solo (Ts), respiração basal microbiana $\left(\mathrm{C}-\mathrm{CO}_{2}\right)$ em sistema orgânico de produção de maçã sob diferentes coberturas do solo em Vacaria (RS)

\begin{tabular}{lccccc}
\hline & Cmic & Corg & Cmic/Corg & $q \mathrm{CO}_{2}$ & $\mathrm{Nmic}$ \\
\hline $\mathrm{Ug}$ & $0,51^{* *}$ & $0,01^{\mathrm{ns}}$ & $0,62^{* *}$ & $-0,35^{* *}$ & $0,47^{* *}$ \\
$\mathrm{Ts}$ & $-0,45^{* *}$ & $-0,83^{* *}$ & $-0,04^{\mathrm{ns}}$ & $0,28^{* *}$ & $-0,32^{* *}$ \\
$\mathrm{C}-\mathrm{CO}_{2}$ & $0,29^{* *}$ & $0,20^{\mathrm{ns}}$ & $0,16^{\mathrm{ns}}$ & $0,56^{* *}$ & $0,02^{\mathrm{ns}}$ \\
$\mathrm{Nmic}$ & $0,70^{* *}$ & $0,35^{* *}$ & $0,56^{* *}$ & $-0,39^{* *}$ & - \\
\hline
\end{tabular}

${ }^{* *}$ Correlações significativas a $1 \%$ de probabilidade. ${ }^{\text {ns }}$ não significativo.

O plástico preto proporcionou maior temperatura e menor umidade no solo (Figura 1) o que foi determinante para o menor conteúdo de Cmic e Corg. Esse processo ocorreu porque o plástico impediu que a superfície do solo recebesse diretamente matéria orgânica fresca e a água da chuva. Como a irrigação da maioria dos pomares na Região Sul do Brasil depende somente do regime regular de chuvas, este tipo de cobertura prejudicou a umidade do solo logo abaixo, sendo esta condicionada apenas a infiltrações pontuais, ocorrendo principalmente nas bordas e em eventuais rasgos ou furos existentes no plástico. O inverso ocorreu com as coberturas orgânicas, que favoreceram e mantiveram a umidade do solo (COSTA et al., 2007), pois facilitam a infiltração da água da chuva pela sua porosidade ao mesmo tempo em que protegem o solo contra o vento e contra a incidência direta dos raios solares (Tu et al., 2006) além de constituírem fontes orgânicas.

Entretanto, nas regiões áridas e semiáridas, onde se faz uso de práticas de irrigação em pontos abaixo do plástico, verifica-se efeito contrário. Neste caso, a cobertura plástica serve como barreira protetora contra a evaporação de água do solo, mantendo-se a umidade (RAMAKRISHMA et al., 2006; Li et al., 2007).

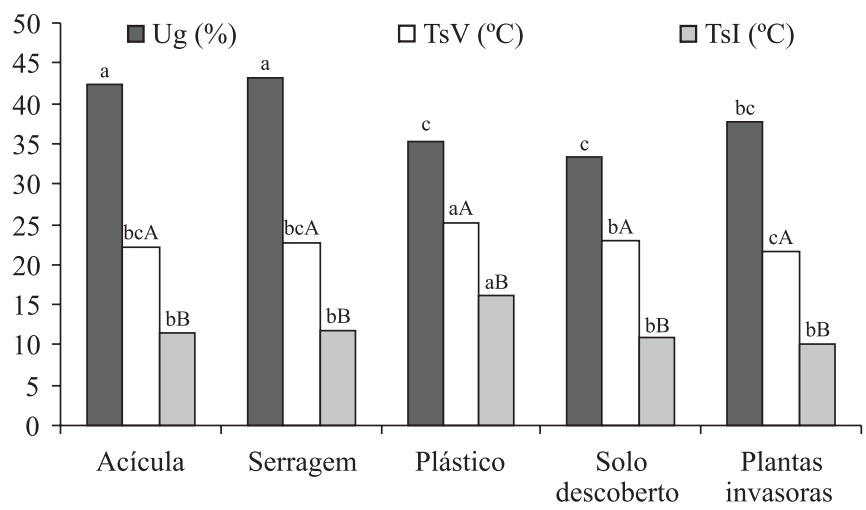

Figura 1. Umidade gravimétrica $(\mathrm{Ug})$ e temperatura do solo no verão (TsV) (fevereiro/2006) e no inverno (TsI) (agosto/2006) em sistema orgânico de produção de maçã sob diferentes coberturas do solo em Vacaria (RS). Letras iguais maiúsculas na linha (época) e minúsculas na coluna (tratamento) não diferem entre si a $5 \%$ de significância pelo teste de Bonferroni. 
Os resultados do presente estudo são similares aos de Oliveira e Souza (2003) e Rossi et al. (2007), ambos em Argissolo Vermelho na fruticultura e TU et al. (2006) em solo franco arenoso na cultura do tomate.

O quociente metabólico microbiano $\left(q \mathrm{CO}_{2}\right)$, que indica a atividade e a estabilidade dos microrganismos no solo, no verão, aumentou na cobertura com plástico preto, quando comparado às coberturas orgânicas (Tabela 3). Verifica-se assim que a população microbiana do solo sob plástico revelou baixa eficiência de utilização do carbono, cerca de $80 \%$ menor em comparação às coberturas orgânicas. No inverno, no entanto, no tratamento com solo descoberto o $q \mathrm{CO}_{2}$ foi maior em comparação às coberturas orgânicas.

$\mathrm{O}$ maior $q \mathrm{CO}_{2}$ constatado na cobertura de plástico no verão e no solo descoberto no inverno foi devido principalmente à pouca umidade e à variação da temperatura verificada no solo sob esses dois tratamentos (Figura 1). A falta de cobertura no solo, onde existe incidência direta da radiação solar, do vento e da chuva, promoveu a formação de um ambiente com menor umidade, desfavorável ao equilíbrio dos microrganismos no solo. Isto pôde ser observado pela existência de uma correlação negativa entre o $q \mathrm{CO}_{2}$ e a umidade, e positiva entre o $q \mathrm{CO}_{2} \mathrm{e}$ a temperatura do solo (Tabela 2).

Tabela 3. Atividade microbiana: respiração basal microbiana $\left(\mathrm{C}-\mathrm{CO}_{2}\right)$ e quociente metabólico $(q \mathrm{CO} 2)$ no verão $($ fevereiro/ 2006) e no inverno (agosto/2006) em sistema orgânico de produção de maçã sob diferentes coberturas do solo em Vacaria (RS)

\begin{tabular}{|c|c|c|c|c|}
\hline \multirow{3}{*}{ Tratamentos } & \multicolumn{2}{|c|}{$\mathrm{C}-\mathrm{CO}_{2}$} & \multicolumn{2}{|c|}{$q \mathrm{CO}_{2}$} \\
\hline & \multicolumn{2}{|c|}{ Época } & \multicolumn{2}{|c|}{ Época } \\
\hline & Verão & Inverno & Verão & Inverno \\
\hline & \multicolumn{2}{|c|}{$\mathrm{mg} 100 \mathrm{~g}^{-1} \mathrm{~h}^{-1}$ de $\mathrm{C}-\mathrm{CO}_{2}$} & \multicolumn{2}{|c|}{$-\mu g C-\mathrm{CO}_{2} \mu \mathrm{g}^{-1} \mathrm{Cmic} \mathrm{g}^{-1}$ solo $\mathrm{h}^{-1}$} \\
\hline Acícula & $0,57 \mathrm{aB}$ & $1,57 \mathrm{abA}$ & $0,98 \mathrm{~b}$ & $1,67 \mathrm{bc}$ \\
\hline Serragem & $1,07 \mathrm{aA}$ & $0,95 \mathrm{abA}$ & $1,39 \mathrm{~b}$ & $0,95 \mathrm{c}$ \\
\hline Plástico & $1,60 \mathrm{aA}$ & $0,82 \mathrm{bA}$ & $5,92 \mathrm{a}$ & $2,41 \mathrm{ab}$ \\
\hline Solo descoberto & $1,24 \mathrm{aA}$ & $1,67 \mathrm{aA}$ & $1,85 \mathrm{ab}$ & $3,05 \mathrm{a}$ \\
\hline Plantas invasoras & $1,19 \mathrm{aA}$ & $1,57 \mathrm{abA}$ & $2,08 \mathrm{ab}$ & $1,96 \mathrm{abc}$ \\
\hline
\end{tabular}

CV (\%) 25,16 41,35

Letras iguais maiúsculas na linha (época) e minúsculas na coluna (tratamento) não diferem entre si a 5\% de significância pelo teste de Bonferroni.

Quanto ao C- $\mathrm{CO}_{2}$, houve interação entre tratamento e época somente na cobertura de acícula (Tabela 3). Isso ocorreu pelo aumento sazonal de carbono microbiano do solo no mesmo período na cobertura de acícula, confirmado pela correlação positiva existente entre o $\mathrm{Cmic}$ e o $\mathrm{C}-\mathrm{CO}_{2}$ (Tabela 2).

No verão, não houve diferenças entre tratamentos para o $\mathrm{C}-\mathrm{CO}_{2}$, porém, no inverno, o solo descoberto apresentou-se maior quando comparado ao solo sob cobertura plástica. Esta maior respiração está correlacionada com o $q \mathrm{CO}_{2}$ (Tabela 2), resultante da falta de proteção sobre o solo.

Devido à atividade microbiana, que indica maior aproveitamento do carbono através das menores perdas indicadas pelo $q \mathrm{CO}_{2}$, o solo sob as coberturas orgânicas recebeu maior conteúdo de carbono na forma orgânica e armazenado na forma de tecido microbiano. De modo contrário, devido à intensa atividade microbiana do solo com menor aproveitamento de carbono e maiores perdas, a cobertura plástica e solo descoberto armazenaram menores conteúdos de carbono na forma orgânica e na forma de tecido microbiano.

\section{Atributos relacionados ao nitrogênio}

O nitrogênio microbiano (Nmic) foi maior no solo com cobertura de acícula e menor na cobertura com plástico preto nas duas épocas amostradas (Tabela 4). Ou seja, em média, a cobertura com acícula permitiu ganho de $35 \%$ em relação ao solo descoberto e $54 \%$ quando comparada ao solo sob a proteção do plástico.

Similar ao que ocorreu para o Cmic, a temperatura, a umidade e o carbono orgânico afetaram os teores de Nmic no solo com a cobertura de acícula e de plástico, fato evidenciado pela correlação existente entre estes atributos (Tabela 2). Observouse ainda uma correlação negativa entre $\mathrm{Nmic}$ e $q \mathrm{CO}_{2}$ o que sugere que quando a população microbiana foi submetida a um ambiente instável como o solo descoberto e o plástico, houve redução na imobilização de nitrogênio. 
Tabela 4. Nitrogênio da biomassa microbiana (Nmic), nitrogênio orgânico total (Ntotal), relação Nmic/Ntotal e nitrogênio mineral amônio $\left(\mathrm{NH}_{4}{ }^{+}\right)$e nitrato $\left(\mathrm{NO}_{3}{ }^{-}\right)$e relação $\mathrm{C} / \mathrm{Nmic}$ no verão (fevereiro/2006) e no inverno (agosto/ 2006) em sistema orgânico de produção de maçã sob diferentes coberturas do solo em Vacaria (RS). Para Ntotal, $\mathrm{Nmic} / \mathrm{N}$ total, $\mathrm{NO}_{3}{ }^{-}, \mathrm{C} / \mathrm{Nmic}$ média das duas épocas

\begin{tabular}{|c|c|c|c|c|}
\hline \multirow{3}{*}{ Tratamentos } & \multicolumn{2}{|c|}{ Nmic } & \multirow{3}{*}{$\begin{array}{l}\text { Ntotal } \\
\text { Média }\end{array}$} & \multirow{3}{*}{$\begin{array}{c}\text { Nmic/Ntotal } \\
\text { Média }\end{array}$} \\
\hline & \multicolumn{2}{|c|}{ Época } & & \\
\hline & Verão & Inverno & & \\
\hline & 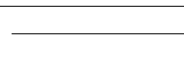 & +2 & $\mathrm{~g} \mathrm{~kg}^{-1}$ & $\%$ \\
\hline Acícula & 110,63 aA & $87,82 \mathrm{aB}$ & $12,11 \mathrm{a}$ & 0,86 a \\
\hline Serragem & $76,23 \mathrm{bA}$ & $77,78 \mathrm{bA}$ & 17,36 a & $0,59 \mathrm{ab}$ \\
\hline Plástico & $53,10 \mathrm{cA}$ & $37,76 \mathrm{~dB}$ & 9,95 a & $0,47 \mathrm{~b}$ \\
\hline Solo descoberto & $76,52 \mathrm{bA}$ & $51,77 \mathrm{cB}$ & 8,51 a & $0,78 \mathrm{ab}$ \\
\hline Plantas invasoras & $88,72 \mathrm{abA}$ & $76,60 \mathrm{bA}$ & 8,87 a & $0,94 \mathrm{a}$ \\
\hline \multirow[t]{2}{*}{$\mathrm{CV}(\%)$} & 7,2 & 43,91 & 28,79 & \\
\hline & \multicolumn{2}{|c|}{$\mathrm{NH}_{4}^{+}$} & $\mathrm{NO}_{3}^{-}$ & $\mathrm{C} / \mathrm{Nmic}$ \\
\hline \multirow[t]{2}{*}{ Tratamentos } & \multicolumn{2}{|c|}{ Época } & Média & Média \\
\hline & Verão & Inverno & & \\
\hline & \multicolumn{3}{|c|}{$\longrightarrow \mathrm{mg} \mathrm{kg}^{-1}$} & \\
\hline Acícula & $4,87 \mathrm{a}$ & $2,05 \mathrm{ab}$ & $3,92 \mathrm{ab}$ & $3,67 \mathrm{bc}$ \\
\hline Serragem & $5,57 \mathrm{a}$ & $1,65 \mathrm{~b}$ & $3,56 \mathrm{ab}$ & $4,81 \mathrm{a}$ \\
\hline Plástico & $3,77 \mathrm{a}$ & $3,38 \mathrm{a}$ & 5,69 a & $3,00 \mathrm{c}$ \\
\hline Solo descoberto & 3,03 a & $1,45 \mathrm{~b}$ & $2,59 \mathrm{~b}$ & $3,93 \mathrm{ab}$ \\
\hline Plantas invasoras & $3,30 \mathrm{a}$ & $2,94 \mathrm{ab}$ & $2,83 \mathrm{~b}$ & $3,59 \mathrm{bc}$ \\
\hline CV $(\%)$ & 32,48 & 34,35 & 13,31 & \\
\hline
\end{tabular}

Letras iguais maiúsculas na linha (época) e minúsculas na coluna (tratamento) não diferem entre si a 5\% de significância pelo teste de Bonferroni.

O maior conteúdo de Nmic verificado no solo sob cobertura de acícula está associado ao maior conteúdo de nitrogênio orgânico compondo este resíduo, $1,44 \mathrm{~g} \mathrm{~kg}^{-1}$, o que corresponde ao dobro da concentração deste elemento na serragem $\left(0,63 \mathrm{~g} \mathrm{~kg}^{-1}\right)$. Esse fato fez com que os microrganismos imobilizassem mais nitrogênio na forma de tecido microbiano.

Tu et al. (2006), ao estudarem coberturas orgânicas, também verificaram maior Nmic no solo sob este tipo de cobertura, aproximadamente $45 \%$ a mais em relação ao tratamento sem cobertura, detectando ainda diferenças entre teores de Nmic, de acordo com a composição da cobertura orgânica em questão.

A relação Nmic/Ntotal foi menor no solo sob plástico quando comparado à acícula e ao solo com plantas invasoras (Tabela 4), significando que esse tipo de cobertura promoveu menor percentagem de $\mathrm{N}$ imobilizado na forma de biomassa microbiana compondo o nitrogênio orgânico total do solo, sugerindo menor proteção contra a lixiviação. Resultado em que também houve influência da variação da temperatura, umidade e teor de carbono orgânico do solo proporcionado pela cobertura plástica (Tabela 2).

Não houve diferenças na concentração de amônio no verão, porém no inverno ocorreu maior valor sob cobertura de plástico preto em comparação à serragem e ao solo descoberto, ou seja, diferenças de mais de $50 \%$. O nitrato $\left(\mathrm{NO}_{3}^{-}\right)$também foi maior no tratamento com o plástico quando comparado ao solo descoberto e ao tratamento com plantas invasoras (Tabela 4). Essa diferença corresponde a $52 \%$ a mais de $\mathrm{NO}_{3}{ }^{-}$no solo sob a cobertura de plástico, o que indica menor perda desta forma de nitrogênio.

Esse processo ocorreu pela maior proteção do solo provocada por este tipo de cobertura, o que dificulta a percolação de água pelo perfil de solo, atuando na redução da lixiviação de nitrato o que diminui a necessidade de adubação por cobertura (STRECK et al., 1994). 
No inverno houve redução de $50 \%$ na concentração de nitrato no solo (Tabela 3), provavelmente devido à maior ocorrência e abundância das chuvas nesta época do ano. Fato associado à maior percolação de água no perfil do solo.

Houve maior relação $\mathrm{C} / \mathrm{Nmic}$ no solo sob cobertura de serragem do que nos tratamentos com acícula, plástico preto e invasoras (Tabela 4), o que sugere maior imobilização de carbono do que nitrogênio no tecido microbiano devido à alta relação $\mathrm{C} / \mathrm{N}$ da serragem utilizada para cobertura.

\section{Atributos relacionados ao fósforo}

O maior acúmulo de fósforo microbiano (Pmic) foi verificado no inverno nos tratamentos com solo descoberto e cobertura com plástico preto (Tabela 5). Nesta mesma época, estes tratamentos tiveram menor relação $\mathrm{C} / \mathrm{Pmic}$, o que significa maior imobilização de fósforo na forma de biomassa microbiana, em média $70 \%$ a mais. Em relação ao fósforo mineral, não houve diferença nos teores de fósforo extraível entre os tratamentos, variando em torno de $12 \mathrm{mg} \mathrm{kg}^{-1}$.

A absorção de fósforo pelas plantas ocorre pelo sistema radicular, portanto, no caso do estudo em questão, o controle total de plantas invasoras nas áreas de cobertura de plástico preto e solo descoberto (Pelizza, 2007) criou uma condição de ausência de outras plantas que, além da macieira, também absorveriam o fósforo disponível. Desta forma, havendo maior oferta de fósforo na superfície do solo, os microrganismos foram beneficiados podendo imobilizar maior quantidade deste elemento na forma de biomassa microbiana. Fato que se evidenciou apenas no inverno pela menor absorção de fósforo devido ao estádio de dormência da planta, e associado à diminuição das atividades metabólicas essenciais da macieira nesta estação do ano (Petri et al., 1996).

Tabela 5. Fósforo da biomassa microbiana (Pmic) e relação C/P microbiana (Cmic/Pmic) no verão (fevereiro/ 2006) e no inverno (agosto/2006) em sistema orgânico de produção de maçã sob diferentes coberturas do solo em Vacaria (RS)

\begin{tabular}{|c|c|c|c|c|}
\hline \multirow{3}{*}{ Tratamentos } & \multicolumn{2}{|c|}{ Pmic } & \multicolumn{2}{|c|}{$\mathrm{C} / \mathrm{Pmic}$} \\
\hline & \multicolumn{2}{|c|}{ Época } & \multicolumn{2}{|c|}{ Época } \\
\hline & Verão & Inverno & Verão & Inverno \\
\hline & 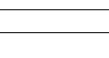 & 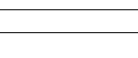 & & \\
\hline Acícula & $5,52 \mathrm{a}$ & $5,75 \mathrm{~b}$ & $45,96 \mathrm{a}$ & $78,56 \mathrm{a}$ \\
\hline Serragem & $4,68 \mathrm{a}$ & $5,78 \mathrm{~b}$ & $69,60 \mathrm{a}$ & 72,66 a \\
\hline Plástico & $4,11 \mathrm{a}$ & $7,23 \mathrm{a}$ & $27,30 \mathrm{a}$ & $19,87 \mathrm{~b}$ \\
\hline Solo descoberto & $4,17 \mathrm{a}$ & $9,35 \mathrm{a}$ & $80,83 \mathrm{a}$ & $25,33 \mathrm{~b}$ \\
\hline Plantas invasoras & $4,18 \mathrm{a}$ & $4,36 \mathrm{~b}$ & $57,91 \mathrm{a}$ & $78,19 \mathrm{a}$ \\
\hline
\end{tabular}

\begin{tabular}{lll}
\hline $\mathrm{CV}(\%)$ & 19,86 & 23,54
\end{tabular}

Letras iguais maiúsculas na linha (época) e minúsculas na coluna (tratamento) não diferem entre si a 5\% de significância pelo teste de Bonferroni.

A ciclagem do fósforo pode ser afetada pelas modificações impostas pelo manejo, tornando-se mais significativa em solos de regiões tropicais com baixos conteúdos de fósforo e alta adsorção (MATos et al., 2006). Nestes solos, a biomassa microbiana atua como reservatório de fósforo impedindo que parte deste elemento incorporado no solo pela adubação se transforme em formas menos disponíveis (VILLANI, 2003). O P é o segundo elemento que mais limita a produtividade das plantas, sendo muito requerido, pois está presente em componentes estruturais das células como nos ácidos nucléicos e fosfolipídios das biomembranas, e também em componentes metabólicos móveis armazenadores de energia, como o ATP (GATiBOni, 2003).

\section{CONCLUSÕES}

1. As coberturas afetam tanto a umidade como a temperatura do solo, propiciando maiores teores de umidade no solo com coberturas orgânicas em comparação com as demais coberturas e o solo descoberto, e as maiores temperaturas no solo com plástico preto.

2. O uso das coberturas orgânicas promove maior quantidade de carbono imobilizado na biomassa microbiana em comparação com a cobertura de plástico preto e o solo descoberto no inverno.

3. O uso da cobertura de acícula sobre o solo propicia maior imobilização de nitrogênio no tecido microbiano comparado com as demais coberturas e o solo descoberto. 
4. O uso do plástico sobre o solo promove menor lixiviação de nitrato comparado com o solo descoberto.

5. O solo descoberto e uso de plástico preto aumenta a imobilização de fósforo no tecido microbiano, entretanto obtêm menor aproveitamento de carbono em relação às demais coberturas.

6. Nas condições deste estudo as coberturas orgânicas propiciam melhores condições para qualidade microbiana do solo.

\section{REFERÊNCIAS}

ANDERSON, J.P.E. Soil respiration. In: PAGE, A.L. (Ed.). Methods of soil analysis. 2.ed. Madison: ASA/SSSA, 1982. p.831-871.

BROOKES, D.S., POWLSON, D.S.; JENKINSON, D.S. Measurement of microbial biomass in phosphorus in soil. Soil Biology \& Biochemistry, v. 14, p.319-329, 1982.

BROOKES, P.C.; LANDMAN, A.; PRUDEN, G.; JENKINSON, D.S. Chloroform fumigation and the release of soil nitrogen: a rapid direct extraction method to measure microbial biomass nitrogen in soil. Soil Biology \& Biochemistry, v.17 p.837-842, 1985.

COSTA, D.M.A.; MELO, H.N.S.; FERREIRA, S.R. Eficiência da cobertura morta na retenção de umidade no Solo. Holos, v.23, p.59-69, 2007.

DE-POLLI, H.; GUERRA, J.G.M. C, N e P na biomassa microbiana do solo. In: SANTOS, G.A. \& CAMARGO, F.A.O. (Ed.) Fundamentos da matéria orgânica do solo: ecossistemas tropicais e subtropicais. Porto Alegre: Gênesis, 1999. p.389-411.

EMBRAPA. Sistema brasileiro de classificação de solos. Brasília: Serviço de produção e informação (SPI/Embrapa), 1999. 412p.

GATIBONE, L.C. Disponibilidade de formas de fósforo do solo às plantas. 2003. 247f. Tese (Doutorado em Biodinâmica dos Solos) - Faculdade de AgronomiaUFSM, Santa Maria.

HAN, Y.X. \& WAN, X. A preliminary analysis on agricultural effects of cotton field mulched with plastic film. Gansu Agricultural Science Technology, v.8, p.14-16, 1995.

IBGE, 2007. www.ibge.gov.br.

JÄGGI, W. Die Bestimmung der $\mathrm{CO}_{2}$-Biulding als Maâ der bonbodenbiologischen Aktivität. Schwiez Landwirtschaft Forchung Band 15, Heft, v.314, p.317-380, 1976.

LI, F.M., SONG, Q.H., JJEMBA, P.K., SHI, Y.C. Dynamics of soil microbial biomass $C$ and soil fertility in cropland mulched with plastic film in a semiarid agro-ecosystem. Soil Biology \& Biochemistry, v.36, p.1893-1902, 2004.
LI, S.Y., W.U., L.H., ZHAO, L.M., LU, X.H., FAN, Q.L., ZHANG, F.S. Influence of continuous plastic film mulching on yield, water use efficiency and soil properties of rice fields under non-flooding condition. Soil \& Tillage Research, v.93, p.370378, 2007.

LIU, X.R. Research on comprehensive techniques for mulched broad beans in dryland farming areas. Agricultural Research in the Arid Areas, v.18, p.40-46, 2000.

MALUCHE-BARETTA, C.R.D. ; AMARANTE, C.V.T.; KLAUBERG-FILHO, O. Análise multivariada de atributos do solo em sistemas convencional e orgânico de produção de maçãs. Pesquisa Agropecuária Brasileira, v.41, n.10, p.15311539, 2006.

MALUCHE-BARETTA, C.R.D.; KLAUBERG-FILHO, O.; AMARANTE, C.V.T.; RIBEIRO, G.M. ; ALMEIDA, D. Atributos microbiológicos e químicos do solo em sistemas de produção convencional e orgânico de maçãs no Estado de Santa Catarina. Revista Brasileira de Ciência do Solo, v.31, p.655-665, 2007.

MATOS, E.S., MENDONÇAS, E.S., VILLANI, E.M.A., LEITE, L.F.C., GALVÃO, J.C.C. Formas de fósforo no solo em sistemas de milho exclusivo e consorciado com feijão sob adubação orgânica e mineral. Revista Brasileira de Ciência do Solo, v.30, p.625-632, 2006.

MONOKROUSOS, N.; PAPATHEODOROU, E.M.; DIAMANTOPOULOS, J.D.; STAMOU, G.P. Soil quality variables in organically and conventionally cultivated field sites. Soil Biology \& Biochemistry, Amsterdam, v.38, p.12821289, 2006.

NIMER, E. Climatologia do Brasil. Rio de Janeiro: Secretaria de planejamento da presidência da republica - Fundação Instituto Brasileiro de Geografia e Estatística, IBGE, 1989. 422p.

OLIVEIRA, C.A.P.; SOUZA, C.M. Influência da cobertura morta na umidade, incidência de plantas daninhas e de broca-do-rizoma (Cosmopolites sordidus) em um pomar de bananeiras (Musa spp.). Revista Brasileira de Fruticultura, v.25, p.345-347, 2003.

PARKINSON, D.; COLEMAN, D.C. Methods for assessing soil microbial populations, activity and biomass-Microbial communities, activity and biomass. Agriculture Ecosystems and Environment, v.34, p.3-33, 1991.

PELIZZA, T.R. Manejo de cobertura do solo e de plantas espontâneas em pomar orgânico de maçãs. 2007. $56 \mathrm{f}$. Dissertação (Mestrado em Produção Vegetal) - Centro de Ciências Agroveterinárias-UDESC, Lages.

PETRI, J. L.; PALLADINI, L. A.; SCHUCK, E.; DUCROQUET, J. P.; MATOS, C. S.; POLA, A. C. Dormência e indução da brotação de fruteiras de clima temperado. Florianópolis: EPAGRI, 1996. 110p.

RAMAKRISHNA, A., TAM, H.M., WANI, S.P., LONG, T.D. Effect of mulch on soil temperature, moisture, weed infestation and yield of groundnut in northern Vietnam. Field Crops Research, Amsterdam, v.95, p.115-125, 2006. 
ROSSI, A.; RUFATO, L.; GIACOBBO, C.L.; COSTA, V.B.; VITTI, M.R.; MENDEZ, M.E.G.; FACHINELLO, J.C. Diferentes manejos da cobertura vegetal de aveia preta em pomar no sul do Brasil. Bragantia, v.66, n.3, p.457-463, 2007.

STRECK, N.A., SCHNEIDER, F.M., BURIOL, G.A. Modificações físicas causadas pelo mulching. Revista Brasileira de Agrometeorologia, v.2, p.131-142, 1994.

TEDESCO, M.J., VOLKWEISS, S.J., BOHNEN, H. Análises de solo, plantas e outros materiais. Porto Alegre: UFRGS, 1995. $174 \mathrm{p}$.

TU, C., RISTAINO, J.B., HU, S. Soil microbial biomass and activity in organic tomato farming systems. Effects of organic inputs and straw mulching. Soil Biology \& Biochemistry, Amsterdam, v.38, p.247-255, 2006.

VANCE, E.D., BROOKS, P.C., JENKINSON, D.S. An extraction method for measuring soil microbial biomass C. Soil Biology \& Biochemistry, v.19, p.703-707, 1987.

VILLANI, E.M.A. Carbono, nitrogênio e fósforo da biomassa microbiana: métodos de avaliação e influência da adubação fosfatada em plantações de eucalipto. 2003. 56f. Tese de Doutorado - UFV, Viçosa, MG.

WALKLEY, A. \& BLACK, A. An examination of degtjareff method for determining soil Organic matter and a proposed modification of the chromic acid titration method. Soil Science, v.37, p.29-37, 1934. 